\title{
Automation of signing contracts for learning in educational units
}

\author{
Agnieszka Sawicka \\ Wrocław University of Economics \\ ul. Komandorska 118/120 53-345 \\ Wrocław, Poland \\ Email:agnieszka.sawicka@ue.wroc.pl
}

\begin{abstract}
Non-public institutions play an important role in higher education. The article discusses the development of administrative repairs through RPA. Based on the robotic process automation, a dedicated project was presented to the automation.
\end{abstract}

\section{INTRODUCTION}

$\mathrm{T}$ ECHNICAL and technological innovations are to contribute to creating better solutions that help in automating administrative processes taking place in educational units. Important in creating innovation and the adaptation of existing solutions has not practiced in the field of higher education, the need is very detailed analysis of the organization and the processes taking place in it. The latest technologies are a challenge for today's universities. They can help create creative solutions that will contribute to the development of the organization, affect the development of the individual and help maintain high quality education. The solution proposed in the article aims to relieve the recruitment staff and the dean's offices. It has to minimize the procedures related to the circulation of documentation, including the signing of an agreement on science and issues of storage. The proposed functionality will also significantly affect the improvement of ecology in the university environment, which is not without significance for more and more aware students in this matter. The project has been prepared based on the operation of a non-public entity, however you can be so universal that it can also be used by public universities - the larger and smaller.

\section{THE ROLE OF RPA TECHNOLOGY AND ERP SYSTEMS IN SUPPORTING THE CIRCULATION OF DOCUMENTATION IN THE EDUCATION INDUSTRY}

Investments in new, intelligent technologies bring development and build the future of innovation in many enterprises both in Poland and on the global market. They also offer specific benefits, such as reducing costs and obtaining more useful data and information. On the subject of RPA technology ( Robotic Process Automation), which enters the administration, with the aim of automating repetitive processes, you can find many interesting publications, but the topic of RPA could also be used to manage the circulation of documentation in a private university. Just as in the case of ERP systems that support the circulation of documentation in the education industry, the RPA technology is designed to automate and replace the repetitive, measurable activities that have been performed so far by man. Thus, it reduces human error and improves the functioning of the entire organization. Replacement works human operator, who celebrates part, cap and processing data, and sentence her to be an idea and solution to the issue of reorganization and documentation university. In the following will be considered a case of signing contracts for storage and science, however, these technologies could also help s to work Bursary department, human resources or the rector of the university and shapes not just the public. This technology is a element of intellectual above process automation (IPA - intelligent process automation), which means that the used solutions are based on logic circuits that perform pre-programmed operations, benefiting from the services about data, which further seems to confirm the legitimacy of considering the introduction of smart technologies to the modern administration of a nonpublic university.

\section{DEDICATED SOLUTIONS FOR REORGANIZING DOCUMENTATION FOR A NON-PUBLIC UNIVERSITY}

As already mentioned, the RPA technology and ERP class systems are designed to support processes and take repetitive tasks. They should also eliminate the risk of clerical errors and improper storage of the most important documents for the university, which is undoubtedly the education contract. In non-public universities, the contract regulates the payment issues and is a set of rules and procedures in specific cases. Therefore, an attempt was made to design a solution based on intelligent technologies, which aims at signing learning contracts by accepting the terms of the contract and storing it in electronic form, limiting highly repetitive activities for the employees of the dean's offices or recruitment departments.

The organization within the scope of the documentation kept, which from 1 October 2019 will be allowed by the Ordinance of the Minister of Science and Higher Education, among others: 
- $\quad$ student ID cards will be issued only in electronic form,

- the hologram of the ID card placed in the fields marked in succession will become a print of strict accountancy,

- reviews of diploma theses will become public,

- in principle, changes in the required elements on the diploma of graduation,

- resignation from issuing decisions on admission to university,

- $\quad$ storing student documents in the so-called electronic student file.

The electronic student file is intended to limit the storage of a large number of documents and to minimize the scope of archiving work at universities . Reducing the number of printing, including paper and toners, will undoubtedly improve the ecology of the university and reduce its costs. Electronic briefcase student carries with it the possibility of storage contracts for science in the work of organizing the deans' offices. Using intelligent technologies, instead of storing a given print in the form of scans of signed contracts for learning in a formal briefcase, you can expand the functionality of the system supporting the dean's office work and extend it with a module that would allow you to sign a learning contract in electronic form. Such a document would go straight to the electronic portfolio of the selected student, thus limiting the scope of procedures and the repetitive work done by the employees of the recruitment departments or dean's offices - in line with the idea of RPA. This solution is admissible under Article 60 of the Civil Code, in which "(...) the will of the person making a legal transaction may be expressed by any behavior of that person that reveals his will in a sufficient manner, including by revealing that will in electronic form ".

The signing of the contract would take place in the following steps:

- to the e-mail address provided in the recruitment form there is a link to the page with a learning contract asking for familiarization with its content,

- after learning the terms of the contract, the student is asked to accept it through the "I accept the terms of the learning contract" button,

- if you select this be an agreement concluded in electronic form to e legal consequences resulting from its signing.

After the student has accepted the provisions, the confirmation along with the contract is sent automatically in the .pdf file to the new system contracting module and the dean's office will be notified and the information about the acceptance of the new contract is sent via e-mail to the mailbox of the indicated department employee, who accepts the contract to the system after acceptance. For universities that do not use the electronic portfolio tool, it would be possible to store files of this type in the cloud or on servers. Dedi- cated extension of the selected non-public university, he would also allow for printing such an agreement, the importance of which would be tantamount to the agreement signed in the traditional way and stored in a standard student carried a briefcase act. The described process is presented in the figures below.

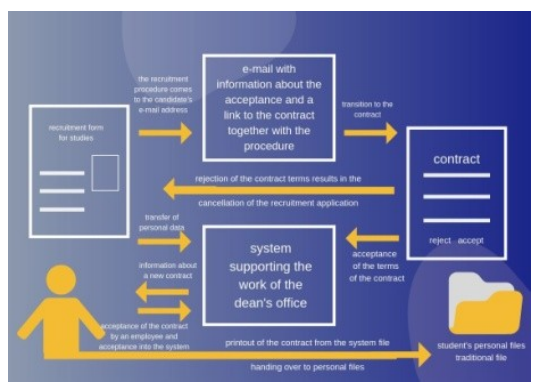

Figure 1: Scheme of electronic procedures for submitting science

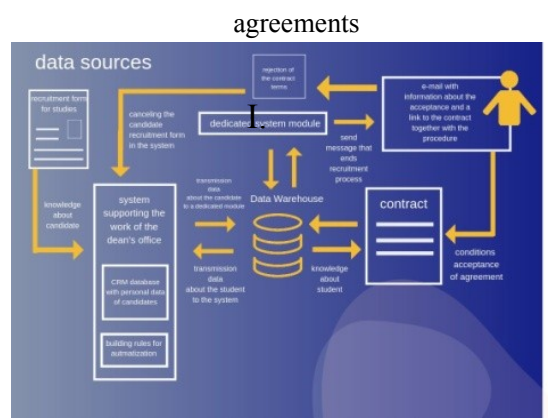

Figure 2: Scheme of data transfer acquiring knowledge between the system and the user

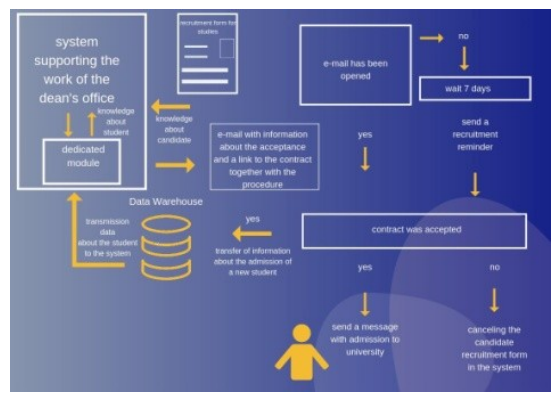

Figure 3: Scheme of automated transfer of information about the contract and admission between the university and candidate

The above diagrams (Fig. 2 and Fig. 3) present it operation of a dedicated solution and its connection with the system together with the automation of messages sent to candidates. These solutions have been designed based on technologies used to build autoresponders . The mechanism introduced into the dedicated contract module, which will be responsible for the preparation of data collected and collected in the data warehouse, will operate on the basis of a group of processes. The following procedures are used to automate the repetitive and tedious processes performed by employees:

- $\quad$ notification of a new recruitment form in the database of the system supporting the university, 
- $\quad$ analysis of the application in terms of missing data,

- $\quad$ error analysis in the provided e-mail addresses and feedback on the incorrect form to the employee,

- $\quad$ determining the potential number of messages with contracts to send,

- $\quad$ automatic sending of messages notifying many candidates at the same time about the acceptance of the application, completion of the recruitment process and the possibility of signing the contrach,

- analysis of the number of sent messages and the number of returned, signed contracts,

- re-sending messages reminding you that you have completed the formalities after passing the specified period,

- $\quad$ recording of reported non-standard cases,

- activities supporting and analyzing the effectiveness of the process.

\section{ADVANTAGES OF THE PREPARED SOLUTION FOR A PRIVATE UNIVERSITY}

In the abovementioned, which became an example to creation of the above mechanism, one of the most important advantages is the simplification of admission procedures for the new student. Dean's office employees are responsible for all types of studies and courses, so the obligation to accept recruitment documents falls on the dean's office. Due to the large number of duties, automation of recurring processes will significantly improve the efficiency of the department, reduce costs and streamline the admission process. The bigger the university, the more benefits it can take from the proposed solution, because the contract module can be freely expanded by the necessary functionalities or create similar solutions dedicated only to the specific needs of organizational units . It is worth noting that filling out contract forms, sending e-mail with identical content and identical links are tasks that can be automated without any problems, thus gaining time for duties that require more attention.

\section{CONCLUSION}

Intelligent technologies undoubtedly bring access both in the field of science and in the socio-economic environment. It is therefore recommended that public and non-public higher education institutions should use solutions that are supported by the latest technological solutions, in order to improve the quality of education, minimize errors in the circulation of administrative documentation and the course of study. Each solution that carries the features of innovation gives the opportunity to meet the expectations of future candidates, thus building the prestige of the university and positively influences the reception of the individual. The introduction of automation of repetitive activities in the administrative departments of universities is a new approach, which may raise some kind of controversy . However, broadening the horizons in the field of modern technologies and introducing its functionalities to departments and organizational units, in which repetitive activities are on the agenda, is caused by the constant need for change, the need to keep up with the changing requirements. The search for creative solutions is the equation between the known, acceptable order and the chaos that change can bring, innovation. Innovation, its implementation and constant search for new solutions, treating it as a direction of action, and as a way of management can dispel fears of disturbing relative stability.

\section{REFERENCES}

[1] Chmielarz W., "Project management and development of management information systems", University of Warsaw WZ Publishing House, Warsaw 2013.

[2] Forbes Technology Council, "10 Strategic Ways To Automate Your Internal Business Workflows", https://www.forbes.com/sites/ forbestechcouncil/2018/05/29/10-strategic-ways-to-automate-your-internal-business-workflows/\# 2dfd6e536972, (accessed: 06/06/2019).

[3] "How Workflow Systems and Automation Are Transforming Life at the Office", https://www.business.com/articles/workflow-automationtransforming-office/, (access : 06/06/2019).

[4] "How Colleges Can Use Workflow Automation to Cut Costs", https:// gravityflow.io/articles/how-colleges-can-use-workflow-automationto-cut-costs/, (accessed: 06/06/2019).

[5] Economic IT, "Computerization of the economic circulation", ed. Korczak J., Dyczkowski M., Łukasik-Makowska B., Publisher of University of Economics in Wroclaw, Wroclaw 2013..

[6] Januszewski A., "Functionality of IT management systems t1.t2.", PWN Scientific Publishers, Warsaw 2006.

[7] "The electronic economy system in the information and knowledge age", ed. Olszak C., Ziemba E., PWN Scientific Publisher, Warsaw 2006.

[8] White Stephen A., "Introduction to BPMN", IBM Corporation, (accessed: 06/06/2019).

[9] Wójtowicz R., "Selected legal, organizational and technological aspects of archiving electronic documents in Polish public institutions, Acquisition of knowledge and knowledge management", Publisher of University of Economics in Wroclaw, Wroclaw 2010. 